\title{
STRUCTURAL-DYNAMIC ORGANIZATION OF PHYTOCENOSES OF FOREST AND FOREST-STEPPE VEGETATION TYPES IN SOUTH- WEST PRE-BAIKAL
}

\author{
Alexander Sizykh ${ }^{1 *}$, Alexander Gritsenyuk ${ }^{3}$, Alexey Shekhovtsov ${ }^{2}$ \\ I*Siberian Institute of Plant Physiology and Biochemistry, Russian Academy of Sciences, 664033, Irkutsk, \\ Lermontova str., 132, Box 317, Russia; \\ ${ }^{2}$ Sochava Institute of Geography, Russian Academy of Sciences, 664033 Irkutsk, Ulan-Batorskaya str., 1, Russia; \\ ${ }^{3}$ Fillipov Agriculture Academy, Buryat Republic, 670024 Ulan-Ude, Pushkina str., 8, Russia;
}

*Corresponding author: Alexander Sizykh, e-mail: alexander.sizykh@gmail.com;

Received February, 2018; Accepted March, 2018; Published April, 2018;

doi: https://doi.org/10.31407/ijees831

UOI license: http://u-o-i.org/1.01/ijees/27237739

\begin{abstract}
The problem of assessment of the state of ecosystems and of the forecast of changes in them in the whole and in vegetation cover structure in particular is basic for modern biogeographic, geobotanical, biocoenotic and ecological studies. Studies of spatial-temporal organization of vegetation reflecting practically all environmental changes during a concrete time period for concrete physical-geographic conditions on any territory requires a synthesis of different research fields for studies of different types of phytocoenoses. At such approach, a phytocoenosis is considered as a system, which forms and develops as a unit and makes interdependent links with systems of other hierarchical level and ecotope conditions. Revealing of phytocoenoses structure and of their response to climatic fluctuations in the zones of contact of different vegetation types, communities typification and classification under transitional environmental conditions allows to determine trends of their formation under modern environmental conditions and to find out the development way of vegetation on the background of dynamics and variability of climate in a concrete region.
\end{abstract}

Key words: forest and forest-steppe, structural-dynamic organization of vegetation, South-West of Pre-Baikal 